\title{
Health and Development of Gay and Lesbian Youths: Implications for HIV/AIDS
}

\author{
ELLEN C. PERRIN, M.D., ${ }^{1}$ and STANLEY SACK, M.D. ${ }^{2}$
}

\begin{abstract}
Health and behavioral issues of gay and lesbian adolescents have recently become a focus of research and interest. A well conceived framework within which to consider thoughtfully the uniqueness of problems faced by homosexual youths and the role of health-care providers is needed. The prevalence, sociocultural history, and theories of origin of the homosexual orientation (biologic, psychoanalytic, and social processes) as well as general issues in adolescent development (biologic, cognitive, and emotional) all contribute to the development of a comprehensive perspective through which better health care and education can be provided. Responsible sexual behavior, depression, and suicide are health-care issues that physicians must be sensitive to and address openly. Up to $50 \%$ of gay youths have "seriously contemplated," suicide and $25 \%$ are estimated to have attempted suicide, according to the literature. In one study, up to $38 \%$ of pediatricians were uncomfortable in caring for homosexual adolescents within their practice. Practical suggestions include reviewing the language in office information forms and brochures providing appropriate literature that demonstrates acceptance of homosexual and bisexual orientations, and avoiding heterosexist bias in questions inquiring about sexuality. Physicians have an opportunity to modify the health and psychosocial risks faced by gay and lesbian youths by restructuring professional settings and accepting broader responsibilities for raising community awareness.
\end{abstract}

\section{OVERVIEW}

$\mathbf{I}_{\mathrm{b}}^{\mathrm{N}}$ N GENERAL, GAY AND LESBIAN YOUTHS have been less visible, less well studied, and less successfully understood than heterosexual adolescents. However, gay and lesbian adolescents have increasingly become a focus of research. There are many reasons for this, but two in particular stand out. First, it has become more acceptable to discuss gay and lesbian issues in general. Second, as the AIDS crisis progressed, it became apparent that many victims in their twenties had actually been infected during their teenage years. All teens are at risk for acquiring HIV infection through the routes of substance abuse and a variety of sexual experiences. Because adolescents who ultimately define themselves as homosexual are some-

\footnotetext{
${ }^{1}$ Developmental and Behavioral Pediatrics, University of Massachusetts Medical Center, Worcester, Massachusetts.

${ }^{2}$ The Fallon Clinic and The University of Massachusetts Medical Center, Worcester, Massachusetts.
} 
Table 1. Definitions of Terms

\begin{tabular}{ll}
\hline Gender identity: & $\begin{array}{c}\text { The perception of oneself as male } \\
\text { or female }\end{array}$ \\
Sexual orientation: & $\begin{array}{l}\text { The individual's pattern of } \\
\text { physical and emotional } \\
\text { attraction } \\
\text { Global description encompassing } \\
\text { gender identity, sexual } \\
\text { orientation, and sexual behavior }\end{array}$ \\
Homosexuality: & $\begin{array}{c}\text { Persistent sexual and emotional } \\
\text { attraction to members of the } \\
\text { same sex }\end{array}$ \\
Homophobia: & $\begin{array}{c}\text { Fear or dislike of people with a } \\
\text { homosexual orientation } \\
\text { Heterosexism: }\end{array}$ \\
$\begin{array}{c}\text { The assumption that only a } \\
\text { heterosexual orientation is } \\
\text { normal }\end{array}$ \\
\hline
\end{tabular}

what more likely to engage in these risky adolescent behaviors than their heterosexual peers, they put themselves at increased risk for HIV infection. It should be clarified that medical risks are associated more with the nature of an individual's sexual activity than with his/her sexual orientation.

The goals of this article are to provide a framework for understanding the special issues that pertain to homosexual youths; to help define the role of health-care providers in the support of gay and lesbian adolescents; and to advise providers as to how to serve as resources for teens and their parents.

\section{PREVALENCE}

It is difficult to estimate what percentage of the population is gay or lesbian. A major problem in determining the prevalence of homosexuality lies in clearly defining the phenome- non. The American Academy of Pediatrics defines homosexuality as "persistent sexual and emotional attraction to members of the same sex and part of a continuum of sexual expression." ${ }^{1}$ Much research acknowledges the range of sexual orientation, especially in adolescents, in whom sexual orientation is developing and fluid.

A few studies have addressed the prevalence of a homosexual orientation (Table 2). Most studies have been criticized for either over- or underreporting the prevalence of homosexuality. There are several reasons for the wide range of reported gay and lesbian population figures. First, the samples studied have varied considerably in age, socioeconomic status, and geographic region. Second, different aspects of sexual expression have been compared; for example, sexual activity compared with self-identification of sexual orientation. Third, the varied methodologies of the studies likely have resulted in very different findings. For example, Remafedi used a confidential, anonymous questionnaire, whereas Laumann used face-toface interviews.

\section{HISTORY}

Over the past several centuries, there has been much discussion and controversy regarding the origin, meaning, and significance of a homosexual orientation. Before the nineteenth century, such discussion took place virtually exclusively in the religious and legal arenas. Beginning in the nineteenth century, the medical community became increasingly involved in exploring and defining homosexuality

Table 2. Reported Prevalence of Homosexuality

\begin{tabular}{llc}
\hline Author (year) & \multicolumn{1}{c}{ Definition } & Frequency \\
\hline Kinsey $(1948)^{2}$ & At least one homosexual experience & $37 \%$ men \\
& Exclusively homosexual for 3 years & $10 \%$ men \\
& & $4 \%$ women \\
Sorenson $(1973)^{3}$ & At least one homosexual experience & $17 \%$ men \\
& & $6 \%$ women \\
Remafedi $(1992)^{4}$ & Unsure of sexual orientation & $10.7 \%$ male adolescents \\
& Predominantly same-sex attractions & $4.5 \%$ male adolescents \\
Laumann $(1994)^{5}$ & Same-sex relations at least once since puberty & $7 \%$ men \\
& & $4 \%$ women
\end{tabular}


largely as an illness to be "treated"; this shift in perspective resulted in individuals who would have been relegated to prisons being confined to insane asylums. Many of the treatments during that period, including genital surgery, lobotomy, drug therapies (e.g., LSD), electroconvulsive therapy, hypnosis, and psychotherapies, persisted to some degree well into the twentieth century. ${ }^{6}$

The words "homosexual" and "heterosexual" were coined in 1868 by Károly Mária Benkert, a German homosexual physician. ${ }^{7}$ It is interesting to note that the label, which was subsequently adopted by the medical community, gave a new status to homosexuals as a group, and social and political organizations began to form in the late nineteenth century. The establishment and growth of such groups, in addition to questioning the motives of the established medical and scientific communities in classifying homosexuality as an illness, have helped to bring about changes in thinking and public opinion regarding homosexuality. As early as the late nineteenth century, a small but significant part of the medical community saw homosexuality as a developmental variation, not as an illness. For example Freud, in a letter to the mother of a homosexual person in 1935, stated: "Homosexuality is assuredly no advantage, but it is nothing to be ashamed of, no vice, no degradation, it cannot be classified as an illness; we consider it to be a variation of the sexual function." 8

The American Psychiatric Association dropped homosexuality from its list of mental disorders in the 1970s. The rationale for this change was as follows: "The crucial issue in determining whether or not homosexuality per se should be regarded as a disorder is not the etiology of the behavior, but its consequences and the definition of mental disorder. A significant proportion of homosexuals are apparently satisfied with their sexual orientation, show no significant signs of manifest psychopathology ..., and are able to function quite effectively, with no impairment in the capacity to love or work." 9

\section{THEORIES}

There are many theories as to the origin of a homosexual orientation. The social process the- ory focuses on homosexuality as a behavior learned from interaction with family and peers; critics of this theory point to the early developmental differences between many individuals who ultimately turn out to be homosexual and those who do not. The psychoanalytic theory focuses on the influence of unresolved issues in the Oedipal or pre-Oedipal period on sexual orientation. A biologic basis of homosexuality is increasingly being investigated through studies that varyingly investigate genetic, hormonal, neurotransmitter-mediated, and neuroanatomic differences in homosexuals as compared with the heterosexual population. ${ }^{10}$ Twin studies have shown increased concordance of homosexual orientation in male identical twins when compared with fraternal twins and more distant relatives. ${ }^{11,12}$ In one intriguing study, Hamer et al. found through pedigree and linkage analyses that gay male members of the families studied inherited certain markers on the long arm of the $X$ chromosome, whereas their heterosexual male counterparts did not. ${ }^{13}$ In another relatively recent study, LeVay found that interstitial nuclei of the anterior hypothalamus were larger in heterosexual men than in homosexual men. ${ }^{14}$ A recent survey of members of the American Psychiatric Association showed overwhelming support for a biologic basis of sexual orientation. ${ }^{15}$

\section{DEVELOPMENT}

It is helpful to explore various hypotheses relating to the emergence of a homosexual orientation in the context of an understanding of general issues in adolescent development. The teenage years are a time of biologic, cognitive, emotional, and social changes that somewhat abruptly descend upon a young person and affect the development of sexuality and its expression. ${ }^{16}$ Table 3 summarizes a brief description of these powerful developmental processes.

\section{Biologic changes}

Changes in hormonal activity are responsible for increased growth and the development of secondary sexual characteristics. This in- 
Table 3. Developmental Changes of Adolescence

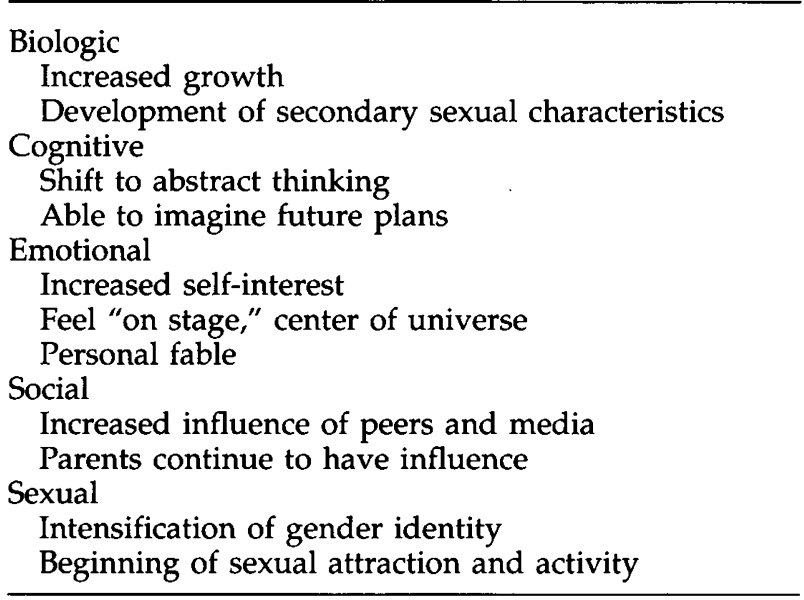

creased activity also causes the onset of menses and has other effects, such as acne and mood changes. Although the timing of puberty affects sexual experience, body image, and selfesteem, it has not been found to be related to a particular sexual orientation.

\section{Cognitive changes}

An important shift in cognitive development during adolescence is from concrete to abstract thinking. Teenagers begin to develop the ability to think hypothetically and to generalize meaning from their experiences. This new coping skill allows them to imagine the future; however, their new conceptual skills still may not meet the challenge of new or unfamiliar situations. Just as a toddler may exhibit regressive behavior when faced with new people or places, teens may resort to predominantly concrete thinking when new challenges are presented to them.

\section{Emotional changes}

Inter- and intrapersonal emotional developments have some bearing on how adolescents handle their evolving sexual feelings. Teenagers generally demonstrate an increased self-interest and may experience themselves "at the center of the universe" and always "on stage." Especially during the early teen years, their relative inability to delay gratification coupled with a belief in the personal fable, "bad things can never happen to me", may put teens at risk.

\section{Social and sexual changes}

During adolescence, development of social relationships and sexuality are central tasks. Peers and messages and images from the media assume great influence and challenge relationships within the family. The role of the family, however, is by no means absent. It has been found that supportive relationships with both peers and family contribute to healthy resolutions of adolescent developmental conflicts and formation of healthy sexuality, and that closeness with one's parents can mitigate negative peer influences. ${ }^{17}$ Gradually, gender identityawareness of oneself as male or female-intensifies. Sexual attraction and activity often begin in middle to late adolescence, and regardless of future sexual orientation, may include same and/or opposite-gender sexual behavior.

In addition to these universal developmental tasks of adolescence, gay and lesbian teenagers may encounter additional challenges in social and sexual development. As homosexual youths begin to realize that they are attracted to members of the same sex, they may wish to seek out more information on sexuality and, especially, homosexuality; such information may not be readily available. There may be limited opportunity for communication and socialization with gay and lesbian peers and healthy adult gay or lesbian role models. Homophobia and heterosexism may be encountered through parents, peers, school, and media.

\section{CASE ILLUSTRATION 1}

Chuck is 22 years old and a college senior. As a child, he was a good student who preferred to spend most of his time alone and indoors. When he did find playmates, he would often prefer role-playing games like "house" to more physical activities. His father, a former college athlete, was disappointed in Chuck's lack of interest in sports and often criticized him and called him a "sissy." To please his parents, Chuck started taking swimming lessons and excelled sufficiently to join a local swim team. 
Chuck became popular in his mid-teens largely because of his academic and athletic ability. By this time he thought he might be gay; however, he felt that his parents and friends would reject him if he discussed these thoughts. Occasionally, his team mates made negative remarks about "queers" or "faggots." At first he tried to make similar comments, but found it increasingly difficult to do so. He started dating one of the girls in his group; 3 months later they began having unprotected intercourse. He initially felt relieved that he might be "straight" after all, but became increasingly dissatisfied with the relationship and broke it off.

Distraught, Chuck's grades began to drop. He gradually withdrew from his friends and spent increasing amounts of time at home in his room. Finally, he was referred to a school counselor. In the course of the initial interview, Chuck told the counselor he thought he was gay. The counselor immediately telephoned his mother and told her about the conversation; she demanded that he see a psychologist immediately to "set him straight."

\section{Stages in the development of homosexuality}

Table 4 describes two models of homosexual identity development. A stage model proposed by Troiden ${ }^{18,19}$ delineates four distinct stages of identity formation. The first stage, sensitization, takes place during the prepubertal years. During this stage, as in Chuck's case in the vi- gnette, many individuals feel different from same-sex peers. They do not define themselves as homosexual; however, some may engage in gender-atypical behavior. ${ }^{20}$ Thus, a girl may be considered a tomboy, shunning interests normally considered feminine and preferring athletic and outdoor activities. A boy may have no interest in sports, but may like to play house or play with dolls. Even adult homosexuals who do not recall having such gender-atypical behavior for themselves generally remember feeling different from their peers. ${ }^{21}$

Stage 2, identity confusion, is a time of anxiety and inner turmoil. Troiden reports that the average age at which homosexual feelings are discovered is around 13 for men and 14 to 16 for women. At this stage, homosexual and heterosexual attractions may coexist both in teenagers who later turn out to become homosexual and in those who become heterosexual. Sexual activity based on this bisexual attraction has been reported to be contributory to the spread of HIV among young women and men. The complexity of homosexual and heterosexual arousal and expression in both adolescents and adults has been relatively poorly understood, contributing further to confusion among adolescents about their own emerging sexual orientation. Troiden states that "society portrays people as either homosexual or heterosexual. ... it is not surprising that adolescent lesbians and gay males are uncertain and confused regarding their sexual orientation."18,19

Gay and lesbian adolescents often become

Table 4. Stages in the Development of Homosexuality

Troiden RR: $1988^{18} 1989^{19}$

Rotheram-Borus and Fernandez: $1994^{22}$

Sensitization: gender-neutral or cross-gender interest;, feeling of being different from same-sex peers (prepubertal)

Identity confusion: anxiety, turmoil; discovery of homosexual feelings; awareness of and response to stigma of homosexuality

Identity assumption: self-definition as homosexual and tolerance of identity; may avoid same-sex contact or engage in stereotyped cross-gender behavior; exploration of homosexual subculture

Commitment: homosexual identity accepted and adopted; disclosure to heterosexuals; many seek to minimize open discussion

Recognizing oneself as lesbian or gay: same-sex fantasies or attractions, initial questioning of sexual orientation; awareness of and response to stigma

Exploring sexual orientation by information gathering: may begin same-gender sexual activity; keep orientation secret; seek contact at gay- or lesbianidentified settings (cruise areas, social service agencies)

Disclosing to others: in many cases, may fear and/or encounter negative consequences such as violence

Becoming comfortable with homosexual orientation: increased self-esteem and positive attitude toward sexuality; possible reduction in risky behavior 
aware increasingly of the stigma attached to homosexuality during middle adolescence, leading to a variety of coping responses. Homosexual teens may disavow their feelings or seek counseling or "cure." They may use varying mechanisms of avoidance, such as failing to form close friendships, avoiding all sexual behavior, engaging in heterosexual behavior, or even "gaybashing" in an attempt to "become" heterosexual. Adolescents may define their homosexuality as just being a temporary phenomenon. Other homosexual teens may choose to accept their sexuality and seek further information.

Stage 3, identity assumption, is reported to take place between the ages of 19 and 21 for males, 21 and 23 for females. Individuals may define themselves as homosexual at this stage and tolerate (but not necessarily accept) this identity. Regular association with other homosexuals and sexual experimentation may take place, possibly within the framework of a homosexual subculture. Problematic responses at this stage include avoidance or minstrelization (stereotyped, gender-inappropriate behavior); for others, affiliation with the gay and/or lesbian community creates a supportive network for healthy development.

In Stage 4, commitment, the homosexual identity is accepted and homosexuality adopted as a way of life. Sexuality and emotionality become fused, and the teen may form a commitment to a loving same-sex relationship. At this stage, which often takes place around age 21 to 24 for men and 22 to 23 for women, disclosure of one's sexual identity to heterosexuals becomes possible (and, in many cases, advisable). Some individuals may attempt to "blend," i.e., they neither announce nor deny their sexual orientation publicly. They adopt a "don't ask; don't tell" stance. Others may acknowledge their sexual orientation, but "cover" by toning down displays of their life-style, and still others may confront social stereotypes directly and work toward social change.

Rotheram-Borus and Fernandez have similarly hypothesized that development of a homosexual identity occurs in stages. ${ }^{22}$ Their proposed four stages include recognizing oneself as lesbian or gay; information gathering; disclosing one's sexuality to others; and becoming more comfortable with one's sexual orientation. This model emphasizes the influence of the environment on the development of a healthy sexual identity. The presence of supportive adults, the availability of information on homosexuality, and the presence of opportunities for interaction with gay and lesbian peers are all said to be protective factors against risky behaviors, especially in the early stages of "coming out." Also potentially important are strong coping mechanisms and high self-esteem. Discovering methods of fostering these traits in adolescents remains an area ripe for future research.

\section{CASE ILLUSTRATION}

Vicky is 24 years old and an AIDS outreach worker. In her early teens, she was a good student and popular in her group of friends. As the girls in her group began showing more interest in boys and started dating, Vicky was surprised that she did not share this interest, and instead was attracted to a girl in the group. When Vicky told the girl that she thought she was in love with her, she was rejected by her and ultimately became alienated from her friends, who began calling her names such as "lezzie."

She began drinking and occasionally used marijuana with a new group of friends. Ultimately, she became depressed and even once considered suicide. In an attempt to "straighten out," Vicky transferred to a new school, where she began dating boys. However, her feelings for members of the same sex persisted.

At age 17, she joined a community softball team, where she was able to "come out" to a few of the team members and began a relationship with a 21-year-old woman. When her parents found out about this relationship, they banished her from her home. Vicky lived on the street for several weeks; during this time, she fell heavily into substance use again. Ultimately, she contacted her lover, moved in with her, and gradually developed a group of friends who accepted and supported her.

Cox and Gallois, in their social identity theory, indicate that development of a healthy sex- 
ual identity is a process involving interaction within established social structures. ${ }^{23}$ Central to their theory are self-categorization (establishment of affiliation with groups by adopting their behaviors, traits, and values) and social comparison (enhancing self-esteem by perceiving the groups with which one is affiliated as "better," at least in some ways, than alternative groups). Thus, a gay male may feel that gay men are more artistic, or a lesbian may find a positive affiliation with a lesbian softball team. This model allows for multiple pathways in the development of a homosexual identity, a concept lacking in some of the pure stage theories. As societal attitudes toward homosexuality evolve, theories may need to be modified to reflect new pathways of homosexual identity development among teenagers.

\section{HEALTH CARE FOR LESBIAN AND GAY ADOLESCENTS}

The primary goal of health care for all adolescents is to promote normal adolescent development, social and emotional well-being, and physical health. This goal is no different for teenagers who are certain of their heterosexual or homosexual orientation, or who are unsure about their sexual orientation. It is not the goal of the primary care provider to learn to "identify" those adolescents who are gay, lesbian, or bisexual. All adolescents need acceptance, support, advice, and modeling from peers, family members, and professionals. It is important for adolescents to understand that there is a large variety of responsible sexual behaviors and a wide range of sexual orientation.

Adolescents who are wondering about the complex feelings they are experiencing with regard to sexual attractions and orientation, and those who know that they are gay, lesbian, or bisexual, are a group of teenagers experiencing to a greater degree the usual degree of upheaval and identity confusion that besets most teenagers in our society. ${ }^{24} \mathrm{~A}$ recent study in Massachusetts documents that most teens do not take advantage of their physician to help them with struggles concerning their sexual orientation. $76 \%$ of college-age youth who identified themselves as gay, lesbian, or bisex- ual reported having talked to some adult(s) during their high school years about their sexual orientation. Of these, only $16 \%$ had spoken with their family or other doctor(s). ${ }^{25}$ In contrast, $38 \%$ of ninth-graders and $42 \%$ of $12-$ graders in a suburban school stated that they would have liked a physician to give them information about homosexuality. ${ }^{26}$

\section{Sexually transmitted diseases and AIDS}

Gay and lesbian teenagers, if they are sexually active, are at risk for the same sexually transmitted diseases (STDs) as are teenagers of heterosexual orientation, as well as for unintended pregnancy. Among the most frightening and widely publicized of the STDs is HIV/AIDS. Sexual activity determines their risk, not sexual orientation, and many teenagers engage in both homosexual and heterosexual activity. They may be at increased risk as well for a number of traumatic and infectious conditions, such as urethritis, anogenital trauma, hepatitis, enteritis, colitis, proctitis, and oropharyngeal conditions. ${ }^{24,27}$

Gay and lesbian teenagers are also at risk for a vast array of psychosocial difficulties. Ubiquitous heterosexism and homophobia may make it difficult to obtain needed information or critical support, and harder still to find people with whom to talk or socialize. The result of repeated rejection and abuse in virtually all areas of their lives can be devastating. Having been told that they are sick, bad, and wrong for being homosexual, gay youths frequently internalize a negative image of themselves. Their own internalized homophobia may be even more harsh than society's stigmatization. When societal homophobia is internalized, adolescents' harsh selfcriticism may result in self-destructive behaviors such as running away from home, homelessness, prostitution, substance abuse, or suicide. For other adolescents, symptoms may be more subtle, such as poor self-esteem, depression, isolation, and school failure.

\section{Socialization}

One of the big problems for homosexual teenagers is social isolation. There is no readily visible peer group for them to identify and socialize with, and their parents may be unwill- 
ing or unable to provide the emotional support they need. They often withdraw from typical adolescent social activities and entertainment and suppress their sexual desires. Few find friends with whom to share their interests. Open relationships or displays of affection with others of the same sex are not tolerated in most youths' homes and social environments, making extreme secrecy a requirement in their developing romantic or intimate attachments. Consequently, homosexual youths have considerable difficulty learning how to establish and maintain intimate relationships in the same way that heterosexual youths do. In one study, $80 \%$ of gay and lesbian youths reported social and emotional isolation, and $28 \%$ eventually dropped out of school. ${ }^{28}$

Although the weight of evidence suggests strongly that homosexuality per se is not related to psychopathology or problematic psychological adjustment, the social stigma still attached to this sexual orientation frequently is emotionally injurious. In an examination of attitudes toward homosexuality, Price reported widespread negative responses to homosexuality from high school and college students, school principals, teachers, coaches, counselors, and the general public. ${ }^{29}$ In a survey of 15- to 19-year-old male high school students self-defined as homosexual or bisexual, $69 \%$ reported verbal or physical abuse in school. ${ }^{30}$ Parental reactions to the disclosure of homosexuality frequently are hostile and rejecting. Half of the lesbian and gay youths interviewed in a high school sample in Minnesota reported that their parents rejected them after they disclosed their sexual orientation. Only $10 \%$ of fathers and $21 \%$ of mothers in this study were reported to be supportive, and $26 \%$ of the youths were forced to leave home because of resultant conflicts. ${ }^{30}$ In some cities, $25 \%$ to $40 \%$ of street kids have been estimated to be homosexual. ${ }^{28,30}$ Depending on the particular study, $32 \%$ to $58 \%$ of gay and lesbian youths have been reported to use alcohol and other drugs as a way of coping with stress. ${ }^{27}$

Numerous reports, although few empirical studies, describe an increased risk of suicide among teenagers struggling with issues related to their sexual orientation. There has been an epidemic increase in suicide among all adoles- cents in our society, increasing by more than 170\% between 1950 and 1980. (The suicide rate for all age groups increased by $20 \%$ during that same time. ${ }^{31}$ Nevertheless, suicidal behavior of gay and lesbian youths is particularly striking and invites intervention by school, mental health, and primary health-care professionals. Although it is extremely difficult to document the association, evidence from numerous studies is converging that gay and lesbian youths are up to three times more likely to attempt suicide than are heterosexual youths and that these youths account for up to $30 \%$ of "successful" adolescent suicides. ${ }^{32,33} \mathrm{Up}$ to $50 \%$ of gay youths have been reported to have seriously contemplated and $25 \%$ to have attempted suicide one or more times before the age of $21 .^{33}$ In a recent study, $68 \%$ of gay and lesbian young people reported contemplating suicide, and $34 \%$ reported that they had made at least one suicide attempt during their high school years. ${ }^{25}$ The true incidence of "successful" suicides associated with questions about sexual orientation, internalized homophobia, and/or social stigmatization cannot be estimated, nor can we know the true rate of completed suicides among youths who have not recognized and/or disclosed their homosexual orientation.

\section{MAKING PROFESSIONAL ENVIRONMENTS MORE SUPPORTIVE}

In a recent survey, $38 \%$ of New England pediatricians reported that they felt uncomfortable about their ability to care for a gay or lesbian adolescent in their practice. ${ }^{34}$ Clearly, some physicians will choose not to be outspoken in support of gay and lesbian youths and their families. It is the responsibility of all physicians to assure that adolescents receive comprehensive, supportive, high-quality health care. If a particular physician feels uncomfortable in providing it, he or she must refer the teen and/or family to a more appropriate provider.

It is not difficult or time-consuming for physicians to create welcoming and supportive environments in their offices for young people struggling with questions about their sexual orientation. Signs or posters assuring confi- 
Table 5. National Resources for Gay/Lesbian Young Adults and Their Parents

\begin{tabular}{|c|c|}
\hline $\begin{array}{l}\text { National AIDS Hotline } \\
\text { (800) } 342-2437\end{array}$ & $\begin{array}{l}\text { Hetrick-Martin Institute for the Protection of Lesbian } \\
\text { and Gay Youth } \\
2 \text { Astor Place }\end{array}$ \\
\hline National Coalition for Gay, Lesbian, and Bisexual Youth & New York, NY 10003-6998 \\
\hline P.O. Box 24589 & (212) $674-2400$ \\
\hline San Jose, CA 95118-4589 & \\
\hline (408) 269-6125 & Lambda Youth Network \\
\hline email: info@outproud.org & $\begin{array}{l}\text { P.O. Box } 7911 \\
\text { Culver City CA } 90233\end{array}$ \\
\hline $\begin{array}{l}\text { National Federation of Parents and Friends of Lesbians } \\
\text { and Gays (PFLAG) }\end{array}$ & email: lambdayn@aol.com \\
\hline 1012 14th Street NW, Suite 700 & Project 10 \\
\hline Washington, DC 20005 & c/o Virginia Uribe, Ph.D. \\
\hline (202) 638-4200 & Fairfax High School \\
\hline email: pflagntl@aol.com & 785D Melrose Avenue \\
\hline & Los Angeles, CA 90046 \\
\hline $\begin{array}{l}\text { National Gay and Lesbian Task Force } \\
1734 \text { 14th Street NW }\end{array}$ & (213) $651-5200$ \\
\hline $\begin{array}{l}\text { Washington, DC 20009-4309 } \\
\text { (202) 332-6483 }\end{array}$ & $\begin{array}{l}\text { National Gay/Lesbian/Bisexual Youth Hotline } \\
\text { (800) 347-TEEN }\end{array}$ \\
\hline
\end{tabular}

dentiality and stating explicitly a policy forbidding homophobic or other hurtful jokes and remarks in this setting inform everyone (staff, patients, and families) that these issues are of critical importance to this physician/office. Even a small rainbow sticker or a pink triangle signals acceptance of diversity in sexual orientation. Among the large variety of information posted on office bulletin boards might be some resources that would be salient for gay and lesbian youths and their families, including information about national (Table 5) and community support groups.

It is also helpful to review office informational forms and brochures to assure that the language is gender-neutral and free of heterosexist bias. Brochures appropriate for office waiting rooms describing the full range of sexual orientation are available and are preferable to those that assume heterosexual orientation. The availability in the office of certain books and magazines that focus on gay and lesbian issues is also a clear indication of the interest of these providers and their acceptance of differences in sexual orientation. Some books often helpful to gay and lesbian teenagers and their families are listed in Table 6.

In the contexts of the offices and institutions in which they work, primary health-care personnel should be careful to assure confidentiality in their routine discussions of emerging sexuality with all adolescents, to use genderneutral language, and to provide evidence of their acceptance of a wide range of sexual orientations (Table 7). All adolescents need "safer sex" education, as well as screening and education as indicated for each adolescent's particular decisions about sexual activity. For

Table 6. BOOKS for Young Adults ANd Parents

Alyson S, Ed. Young, Gay and Proud. Boston, MA: Alyson Press, 1991.

Bass E, Kaufman K. Free Your Mind. New York, NY: Harper Collins, 1996.

Borhek MV. Coming Out To Parents: A Two-Way Survival Guide for Lesbians and Gay Men and Their Parents. Cleveland, OH: Pilgrim Press, 1993.

Borhek MV. My Son Eric. New York, NY: Pilgrim Press, 1984.

Cohen S, Cohen D. When Someone You Know Is Gay. New York, NY: Dell, 1989.

Eichberg R. Coming Out: An Act of Love. New York, NY: Dulton, 1990.

Fairchild B, Hayward N. Now That You Know: What Every Parent Should Know About Homosexuality. Orlando, FL: Harcourt Brace Publishing, 1989.

Griffin CW, Wirth AG, Wirth MJ. Beyond Acceptance: Parents of Lesbians and Gays Talk About Their Experience. New York, NY: St. Martin's Press, 1990.

Heron A, Ed. Two Teenagers in Twenty: Writings by Gay and Lesbian Youth. Boston, MA: Alyson Press, 1994.

Hunt M. Gay: What Teenagers Should Know About Homosexuality and the AIDS Crisis. New York, NY: Farrar/Strauss/Giroux Publishing, 1987.

Jennings K. Becoming Visible: A Reader in Gay and Lesbian History for High School and College Students. Boston, MA: Alyson Press, 1994. 
Table 7. Questions about Sexualtix

It is helpful to reassure all adolescents that questions about sexuality are a routine part of the health supervision visit. Questions such as these can be included in a written health history form or be part of an office interview.

Some appropriate questions are listed as follows:

Some of my patients your age are dating-some boys, some girls, some both. Are you interested in dating?

Have you ever dated or gone out with someone?

Have you ever been attracted to any boys or girls?

Is there any special person in your life outside of your family?

There are many ways of being sexual with another person: petting, kissing, hugging, as well as sexual intercourse. Have you had any kinds of sexual experiences? If so, were they with boys or girls or both?

Are you currently involved in a steady relationship with a boy or a girl?

How do you protect yourself and your partner against sexually transmitted diseases (and pregnancy)?

Do you have any concerns about your sexual feelings or the sexual things you have been doing?

Have you discussed these concerns with your parents or any other adults? Any of your friends?

Do you consider yourself to be gay/lesbian, bisexual, or heterosexual (straight)?

those adolescents who indicate the desire for more information and/or resources regarding lesbian and gay issues, the primary care provider should be able to provide recommended written information (Table 6) and local and/or national resources (Table 5), as well as to offer support for adolescents faced with or anticipating conflicts with families and/or friends.

A particular caution with regard to the maintenance of confidentiality regards referral and consultation policies. It is essential that the primary care provider assure that his or her colleague be respectful of the teenager's sexual orientation and discuss with the adolescent and his or her family exactly what they wish disclosed to these colleagues. Notations in office and/or hospital charts present yet another complex decision, the resolution of which may depend on the particular office, institution, and community, but also may be discussed with the teenager and his or her family if the situation warrants it. It is important to remember that teenagers can give independent legal consent for evaluation and care in most states where issues of sexuality (and substance use and mental health) are concerned. Records also can be kept confidential in these domains.

\section{BROADER RESPONSIBILITIES}

In addition to providing support, care, and advice for their adolescent patients and their parents, it is important that health-care providers be visible opinion leaders in their communities. Primary care providers can help to raise the awareness and acceptance of school and other community members regarding issues relevant to gay and lesbian teenagers. They can be important supporters of schoolbased and community-based support groups for gay and lesbian students, their friends, and their parents, and leaders in the development of AIDS prevention and education efforts. In addition, those who choose to address these issues in greater depth may become important advocates for the inclusion of reading materials, curricular materials, and publications regarding gay and lesbian issues in school and community libraries, as well as for the development and presentation of continuing education programming for health care and educational personnel.

Physicians are powerful sources of information and opinion. Their support of adolescents as they develop a mature sexual orientation will have an important impact on young people, their parents, and other adults in the community. Their leadership is a critical ingredient in modifying the medical and psychosocial risks still faced by gay and lesbian teenagers, adults, and their families. 


\section{REFERENCES}

1. Committee on Adolescence. Homosexuality and Adolescence. Pediatrics 1993;94:631-634.

2. Kinsey A, Pomeroy WB, Marin CE. Sexual behavior in the human male. Philadelphia: WB Saunders, 1948.

3. Sorenson RC. Adolescent sexuality in contemporary America. New York: World Publishing, 1973, pp. 285-295.

4. Remafedi G, Resnick M, Blum R, et al. Demography of sexual orientation in adolescents. Pediatrics 1992; 89:714-721.

5. Laumann EO, Gagnon JH, Michael RT, Michaels S. The social organization of sexuality: sexual practices in the United States. Chicago: University of Chicago Press, 1994.

6. Katz JN. Gay American history: lesbians and gay men in the USA. New York: Penguin Books, 1992.

7. Katz JN. Gay/lesbian almanac: a new documentary. New York: Harper \& Row, 1983.

8. Freud S. Historical notes: a letter from Freud. Am J Psychiatry 1951;107:286-287.

9. American Psychiatric Association. Diagnostic and statistical manual of mental disorders, 3rd ed. New York: American Psychiatric Association, 1978.

10. Pillard RC, Bailey JM. A biologic perspective on sexual orientation. Psychiatr Clin North Am 1995;18:71-84.

11. Eckert ED, Bouchard TJ, Bohlen J, et al. Homsexuality in twins reared apart. Br J Psychiatry 1986;148:421-425.

12. Kallman FJ. Comparative twin study on the genetic aspects of male homosexuality. J Nervous Mental Dis 1952;115:283-298.

13. Hamer DH, Hu S, Magnuson VL, et al. A linkage between DNA markers on the $X$ chromosome and male sexual orientation. Science 1993;261:321-327.

14. LeVay S. A difference in hypothalamic structure between heterosexual and homosexual men. Science 1991;253:1034-1037.

15. Vreeland CN, Gallagher BJ, McFalls JA. The beliefs of members of the American Psychiatric Association on the etiology of male homosexuality: a national survey. J Psychol 1995;129:507-517.

16. Neinstein L. Adolescent health care: a practical guide. Baltimore: Williams and Wilkins, 1996.

17. Peterson AC, Leffert N, Grahan BL. Adolescent development and the emergence of sexuality. Suicide and life-threatening behavior 1994;25(suppl):4-17.

18. Troiden RR. Homosexual identity development. J Adolescent Health Care 1988;9:105-113.

19. Troiden RR. The formation of homosexual identities. J Homosexuality 1989;17:43-73.

20. Bailey JM, Zucker KJ. Childhood sex-typed behavior and sexual orientation: a conceptual analysis and quantitative review. Dev Psychol 1995;31:43-55.

21. Bell AP, Weinberg MS, Hammersmith SK. Sexual preference: its development in men and women Bloomington, IN: Indiana University Press, 1981.

22. Rotheram-Borus MJ, Fernandez MI. Sexual orientation and developmental challenges experienced by gay and lesbian youths. Suicide life-threatening behav 1994;25 (suppl): 26-33.

23. Cox S, Gallois C. Gay and lesbian identity development: a social identity perspective. J Homosexuality 1996;30:1-30.

24. Paroski PA. Health care delivery and the concerns of gay and lesbian adolescents. J Adolescent Health Care 1987;8:188.

25. Campbell L, Perrin EC. Social support for gay and lesbian adolescents. Presentations at Annual Meetings of Society for Research in Child Development, April 6, 1997, and Ambulatory Pediatric Association, May 2, 1997.

26. Rawitscher LA, Saitz R, Friedman LS. Adolescents' preferences regarding human immunodeficiency virus (HIV)-related physician counseling and HIV testing. Pediatrics 1995;96:52-58.

27. Remafedi G. Adolescent homosexuality: psychosocial and medical implications. Pediatrics 1987;79:331-337.

28. Hetrick ES, Martin AD. Developmental issues and their resolution for gay and lesbian adolescents. J Homosexual 1987;14:25-43.

29. Price JH. High school students' attitudes toward homosexuality. J School Health 1982;52:469-474.

30. Remafedi G, Farrow J, Deisher R. Risk factors for attempted suicide in gay and bisexual youth. Pediatrics 1991;87:869-875.

31. Centers for Disease Control, Center for Environmental Health. Youth suicide surveillance report. Atlanta, GA: Department of Health and Human Services, 1986.

32. Report of the Secretary's Task Force on Youth Suicide. DHHS Publication No. 89-1621. Rockville, MD: Alcohol, Drug Abuse, and Mental Health Administration, 1989.

33. Remafedi G. Death by denial: studies of suicide in gay and lesbian teenagers. Boston: Alyson Publishing, 1994.

34. Perrin EC. Pediatricians' attitudes towards caring for psychosocial issues in practice. Presentations at Annual Meetings of Society for Research in Child Development, April 4, 1997, and Ambulatory Pediatric Association, May 5, 1997.

Address correspondence to:

Ellen C. Perrin, M.D.

Developmental and Behavioral Pediatrics

University of Massachusetts Medical Center

Worcestor, MA 01610 